\title{
Superação da dormência de sementes de Schinopsis brasiliensis
}

\author{
Dormancy loss in seed of Schinopsis brasiliensis
}

Maria da Conceição Prado de Oliveira' Geraldo José de OliveiraII

\begin{abstract}
Schinopsis brasiliensis Engler (Anacardiaceae), RESUMO popularmente conhecida como baraúna ou brauna, é uma árvore típica da caatinga, tem sementes de germinação difícil e demorada. $O$ trabalho teve por objetivo avaliar a germinação das sementes de $\boldsymbol{S}$. brasiliensis e indicar técnicas que tornem mais eficiente esse processo. Os frutos foram coletados em novembro de 2001 (período de frutificação), na Fazenda Juriti, município de Caruaru, Pernambuco, Brasil, na região semiárida. Foram utilizados frutos recém-coletados, testando-se: frutos com e sem epicarpo e mesocarpo, lavados e sem lavar. Diferentes metodologias foram usadas para superar a dormência do endocarpo de frutos armazenados por trinta dias em saco de papel Kraft, em câmara fria e seca $\left(15 \pm 2^{\circ} \mathrm{C}\right.$, $50 \% U R)$. Em função dos resultados apresentados, pode-se concluir que a melhor maneira de se obter uma germinação mais regular, rápida e completa das sementes de $\boldsymbol{S}$. brasiliensis é a remoção do epicarpo e do mesocarpo e a realização da semeadura após 25 a 30 dias de armazenamento (pré-secagem) em areia úmida.
\end{abstract}

Palavras-chave: germinação, escarificação mecânica, escarificação ácida, velocidade de germinação.

\section{ABSTRACT}

Schinopsis brasiliensis Engler (Anacardiaceae), commonly known as "baraúna or brauna", a typical "Caatinga" tree. It presents seeds with difficult and delayed germination. This research had the objective to evaluate the germination seeds of $\boldsymbol{S}$. brasiliensis, and to suggest techniques that make more efficient the germination process. The fruit were collected on November 2001 (fructification period) in
Juriti Farm, municipality of Caruaru, Pernambuco State, Brazil, in semi-arid region. It were used newly collected fruit to the tests of: fruit with and without epicarp and mesocarp, washed fruit and not washed fruit. Different methods were used to overcome the endocarp dormancy of fruit stored during 30 days in a cold and dry chamber $\left(15 \pm 2^{\circ} \mathrm{C}, 50 \%\right.$ UR) kept in Kraft paper bags. According to the results, the best way to get a regular, fast and completed germination of $\boldsymbol{S}$. brasiliensis is the extraction of epicarp and mesocarp and to sow in humid sand after 25 to 30 days stored (pre-drying).

Key words: germination, mechanical scarification, acid scarification, germination velocity

A espécie em estudo, Schinopsis brasiliensis Engler (braúna ou baraúna, como é conhecida), é uma árvore típica da caatinga, com 10$12 \mathrm{~m}$ de altura, cerca de $60 \mathrm{~cm}$ de diâmetro e com ramos providos de espinhos fortes (ENGLER, 1879), ocorrendo em quase toda a área das caatingas da Bahia à Paraíba, com poucos representantes do Rio Grande do Norte ao Piauí (ANDRADE-LIMA, 1989). Sua madeira é de grande valor econômico, apresenta cerne duro, resistência a fungos xilófagos (PAES et al., 2004) e, no passado, foi bastante utilizada para a feitura de dormentes e vigamentos (ANDRADE-LIMA, 1989). O emprego irracional para esses e outros fins fez com que o seu nome fosse incluído na lista oficial das espécies ameaçadas de extinção (BRASIL, 1992b). O fruto de baraúna é uma sâmara com as camadas do

IDepartamento de Biologia, Centro de Ciências da Natureza (CCN), Universidade Federal do Piauí (UFPI). Campus Universitário Petrônio Portela, Ininga, 64049-550, Teresina, PI, Brasil. E-mail: pradoliveira@hotmail.com. Autor para correspondência.

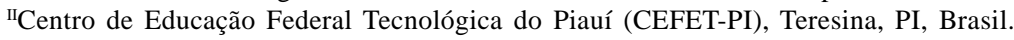


pericarpo marcadamente diferenciadas: epicarpo membranoso, mesocarpo esponjoso e endocarpo lenhoso “ósseo” e impermeável à água (PRADO et al., 1996). O endocarpo envolve a semente e não se desprende facilmente, formando o que BARROSO et al. (1999) definiram como pirênio. Essa camada funciona como uma barreira', dificultando a germinação e, sob condições naturais, essa pode ser uma estratégia para que a espécie escape da seca (ANGEVINE \& CHABOT, 1979).

No laboratório, a utilização de métodos para a superação da dormência pode permitir uma germinação mais regular, rápida e completa das amostras de sementes de uma espécie (BRASIL, 1992a). A escolha do método a ser aplicado depende do tipo de dormência. No caso das espécies dotadas de sementes com envoltório duro e impermeável, como $S$. brasiliensis, recomenda-se: a imersão em solventes (por exemplo água quente), escarificação mecânica, escarificação com ácido e resfriamento rápido (POPINING 1985).

Pouco se sabe sobre a germinação das sementes de $\boldsymbol{S}$. brasiliensis sob condições naturais e/ ou controladas. Neste trabalho, objetivou-se avaliar a germinação das sementes de baraúna e indicar técnicas que possam acelerar esse processo. Informações como essas poderão ser úteis para sua indicação em programas de reposição de áreas devastadas pela ação antrópica.

Para o presente estudo, frutos maduros de S. brasiliensis foram coletados em novembro de 2001 (período de frutificação), diretamente das árvores em uma população natural, localizada na Fazenda Juriti, no município de Caruaru, na subzona fisiográfica do agreste pernambucano.

Após 24 horas da coleta dos frutos, retirouse uma amostra de 380 unidades, separando-a em quatro lotes, para submetê-los aos seguintes tratamentos: AFrutos íntegros lavados em água corrente, por cinco minutos, e mais três vezes com água destilada; B Frutos com epicarpo e mesocarpo removidos manualmente; $\mathrm{C}$ - Frutos com epicarpo e mesocarpo removidos e lavados por três vezes com água destilada; D - Frutos íntegros (controle).

Para avaliar o melhor método para superar a dormência causada pelo endocarpo duro, foram utilizados 380 frutos armazenados por 30dias em saco de papel Kraft, em câmara fria e seca $\left(15 \pm 2^{\circ} \mathrm{C}, 50 \% \mathrm{UR}\right)$. Removeram-se, manualmente, o epicarpo e o mesocarpo dos frutos. Em seguida, os pirênios foram separados em quatro lotes e submetidos aos tratamentos: A água a $100^{\circ} \mathrm{C} / 2$ minutos - os pirênios foram envolvidos com gases presos a um cordão de náilon e imersos em banho-maria regulado, sendo, em seguida, esfriados e lavados com água destilada; B - escarificados, com lixa de ferro - os pirênios foram escarificados, na posição da emissão da raiz, e lavados por três vezes com água destilada; C - escarificação com ácido clorídrico (HCl) a 10\% /10 minutos - os pirênios foram imersos em 300mL de ácido, sendo, em seguida, lavados com água corrente por 15 minutos e lavados novamente por duas vezes com água destilada; D - Frutos com epicarpo e mesocarpo removidos - controle.

Após os tratamentos, os frutos foram semeados em bandejas de plástico contendo areia lavada e esterilizada em autoclave ventilado, a $120^{\circ} \mathrm{C} /$ 30min. As bandejas foram distribuídas em blocos casualizados no balcão do laboratório $\left(25 \pm 2^{\circ} \mathrm{C}\right.$ e $50 \pm 5 \%$ UR). Diariamente, registraram-se as sementes germinadas (critério de germinação: aparecimento na superfície do solo da parte aérea da plântula) e cada bandeja umedecida com $100 \mathrm{~mL}$ de água. O tempo médio foi estimado segundo EDMOND \& DRAPALA (1965) e, para comparação dos tratamentos, aplicou-se o teste de Tukey a 5\% de probabilidade.

Observações efetuadas na população de $\boldsymbol{S}$. brasiliensis, ocorrente na Fazenda Juriti, mostraram índice baixo de plantas jovens sob as copas das árvores (PRADO-OLIVEIRA, 1993). Sabe-se que compostos químicos inibidores de germinação de sementes podem ser lançados no ambiente exudados das folhas, raízes, caules ou frutos (PULMAN, 1983). Extratos de folhas de baraúna inibiram a germinação de sementes de espécies nativas e cultivadas (TAVARES, 1982). Estudos fitoquímicos sugeriram que o ácido gálico (grupo dos taninos hidrossolúveis) foi o responsável pela inibição da germinação das sementes avaliadas (SOUZA, 1990). Outros estudos mostraram que os frutos maduros também apresentam compostos do grupo dos taninos pirogálicos (2,17g de ácido tânico $100 \mathrm{~mL}^{-1}$ de solução aquosa) (PRADO-OLIVEIRA, 1993). A remoção do epicarpo e mesocarpo elevou a germinação das sementes de 4 para 19\% e reduziu o tempo médio a praticamente a metade (Tabela 1), sugerindo a presença dessas substâncias, nessas camadas. Para eliminar essas substâncias recomendase lavagem em água corrente (POPININGIS, 1985).

A análise dos parâmetros (percentual e tempo médio de germinação) de avaliação para determinar o melhor método para superar a dormência causada pelo endocarpo duro mostrou que somente o tratamento com água quente diferenciou-se do controle (Tabela 1). A intolerância à água quente por um período tão curto corrobora a hipótese de que o pericarpo tem papel importante na sobrevivência das sementes durante a estiagem na caatinga. A baraúna frutifica no 
Tabela 1 - Germinação de sementes de Schinpsis brasiliensis Engl. recém coletadas (período de frutificação: novembro, 2001) e armazenadas por trinta dias em saco papel Kraft, em câmara fria e seca ( $\left.15 \pm 2^{\circ} \mathrm{C}, 50 \% \mathrm{UR}\right)$.

\begin{tabular}{|c|c|c|}
\hline \multicolumn{3}{|c|}{ Sementes recém coletadas } \\
\hline Tratamento & Germinação (\%) & Tempo médio (dias) \\
\hline frutos íntegros lavados com água corrente e água destilada & $8 \mathrm{~B}$ & $15 \mathrm{~A}$ \\
\hline frutos íntegros sem lavar (controle) & $4 \mathrm{~B}$ & $17 \mathrm{~A}$ \\
\hline frutos com epicarpo e mesocarpo removidos & 19A & 9B \\
\hline frutos com epicarpo e mesocarpo removidos e lavados & $19 \mathrm{~A}$ & $8 B$ \\
\hline germinação das sementes recém coletadas (média) & 13 & 12 \\
\hline coeficiente de variação (CV\%) & 61,4 & 36,1 \\
\hline \multicolumn{3}{|c|}{ Sementes armazenadas } \\
\hline Tratamento & Germinação (\%) & Tempo médio (dias) \\
\hline sementes com endocarpo integro (controle) & $64 \mathrm{~A}$ & $9 \mathrm{~A}$ \\
\hline escarificação mecânica (lixa de ferro) & $56 \mathrm{~A}$ & $8 \mathrm{~A}$ \\
\hline escarificação ácida (HCl 10\%-10min) & $68 \mathrm{~A}$ & $8 \mathrm{~A}$ \\
\hline tratamento com água quente $\left(100^{\circ} \mathrm{C}-2 \mathrm{~min}\right) *$ & OB & - \\
\hline germinação das sementes armazenadas (média) & 63 & 8 \\
\hline coeficiente de variação das médias (CV\%) & 9,7 & 6,9 \\
\hline
\end{tabular}

Médias seguidas pela mesma letra na coluna não diferem entre si pelo teste de Tukey a 5\% de probabilidade.

*Tratamento não incluído nos cálculos da avaliação das sementes armazenadas.

período seco, e os frutos podem permanecer no solo até a chegada das chuvas, intervalo que dura até onze meses e a temperatura do solo alcançar $60^{\circ} \mathrm{C}$ (GUIMARÃES DUQUE, 1973). Sob essas condições, algumas sementes sobrevivem graças ao envoltório e às estruturas anexas, os quais podem exercer um papel isolante, tanto face ao aquecimento, quanto à perda de água (LABORIAU, 1983). A análise mostrou também que o tratamento com escarificação ácida foi ineficaz, considerando-se o sucesso do método com sementes de outras espécies com tegumento duro (DUARTE, 1978). Supõe-se que o tempo de exposição ao ácido e/ou a concentração foram insuficientes para influenciar o percentual e a velocidade de germinação das sementes. O pré-tratamento, utilizandose lixa para romper o endocarpo, também não foi satisfatório. Ao cortar o endocarpo dos frutos de baraúna com alicate e semeá-los em caixas plástica sobre papel “kimpak”, FELICIANO(1989) obteve 70\% de germinação, resultado não muito diferente do mostrado na tabela 1 . Os frutos de baraúna armazenados durante 30 dias em câmara fria e seca apresentaram 63\% de germinação média (CV\% $=9,7$ ), com ou sem tratamento ao remover-se parte do pericarpo e semear os frutos em areia úmida (Tabela 1). $\mathrm{O}$ acompanhamento do armazenamento durante dez meses, sob essas mesmas condições, mostrou que não houve efeito significativo do tempo de armazenamento na germinação, após 30 dias (PRADO-OLIVEIRA 1993). Frutos armazenados em laboratório por 25 dias e semeados em areiaúmida apresentaram 75\% de germinação (SILVA et al. 1988).
A combinação da desidratação com o congelamento em nitrogênio líquido, seguido de descongelamento, foi considerada eficaz para a germinação (52 a 55\%) de $\boldsymbol{S}$. brasiliensis. SALOMÃO et al. (2001) sugerem que o congelamento proporcionou o amolecimento do endocarpo, melhorando a absorção de água e as trocas gasosas. Para os resultados apresentados na tabela 1, supõe-se que a câmara fria e seca possa ter provocado rachaduras no endocarpo, enquanto a remoção do epicarpo e mesocarpo eliminou os inibidores de germinação e a areia úmida promoveu o amolecimento do endocarpo. Assim, para se obter uma germinação mais regular, rápida e completa de $\boldsymbol{S}$. brasiliensis, deve-se manter seus frutos à sombra (présecagem) por 25 a 30 dias, remover parte do pericarpo e semear o pirênio em areia úmida.

\section{REFERÊNCIAS}

ANDRADE-LIMA, D. Plantas das Caatingas. Rio de Janeiro: Academia Brasileira de Ciências, 1989. 243p.

ANGEVINE, M.W; CHABOT, B.F. Seed germination syndromes. In: SOLBRIG, O.T. et al. Topics in plant population biology. N ew York: Columbia University, 1979. p.189-206.

BARROSO, G.M. et al. Frutos e sementes: morfologia aplicada à sistemática de dicotiledôneas. Viçosa: Universidade Federal de Viçosa (UFV), 1999. 443p.

BRASIL. Ministério da Agricultura e da Reforma Agrária. Regras para análise de sementes. Brasília: SNDA/DNDV/ CLAV, 1992a. 365p.

BRASIL, Portaria nº 37-N/1992, de 3 de abril de 1992. IBAMA 
(Ministério do Meio Ambiente). Diário Oficial da União, Brasília, 07 de abril 1992b. Seção 3, p.204.

DUARTE, M.J. Análise de sementes de seis espécies autóctones e alternativas para o reflorestamento na região semi-árida do Nordeste brasileiro. 1978. $153 f$. Dissertação (Mestrado em Engenharia Florestal) -Universidade Federal do Paraná, Curitiba.

EDMOND, J.B.; DRAPALA, W.J. The effects of temperature, sand and soil, and acetone on germination of okra seed. Proceedings of the American Jornal Society for Horticultural Science, v.71, p.428-434, 1965.

ENGLER, A. Anacardiaceae. Flora brasilienses, v.12, n.2, p.367-418, 1879.

FELICIANO, A.L. Estudo da germinação de sementes e desenvolvimento de mudas, acompanhado de descrição morfológica de dez espécies arbóreas ocorrentes no semi-árido nordestino. 1989. 30f. Dissertação (Mestrado em Ciências Florestais) -Universidade Federal de Viçosa, Viçosa.

GUIMARÃES DUQUE, J. Solo e água no polígono das secas. 4.ed. Fortaleza: Ministério da Viação e Obras Contra as secas, 1973. 310p. (Publicação 154, Série I-A).

LABORIAU, L.G. A germinação das sementes. Washington: OEA, 1983. 174p. (OEA, Série de Biologia: Monografia, 24).

PAES, J.B.et al. Resistência natural de nove madeiras do semiárido brasileiro a fungos xilófagos em condições de laboratório. Revista Árvore, v.28 n.2. p.275-282, 2004
POPINIGIS, F. Fisiologia da semente. Brasília: AGIPLAN, 1985. 289p.

PRADO-OLIVEIRA, M. da C. Aspectos morfo-anatômicos da unidade de dispersão, germinação e crescimento de Schinopsis brasiliensis Engl. (baraúna) Anacardiaaceae. 1993. 132f. Dissertação (Mestrado em Botânica) Universidade Federal Rural de Pernambuco, Recife.

PRADO, M. da C.G do et al. Aspectos morfo-estruturais da unidade de dispersão de Schinopsis brasiliensis Engl. "Baraúna" (Anacardiaceae). Boletim da Sociedade Broteriana, série 2, v.67, p.187-197, 1996.

PULMAN, A.R. Alellopathia chermical: nature's herbicides in action. Michigan: Michigan State University, 1983. 11p.

SALOMÃO, A.N. et al. Métodos para superar a dormência em brauna (Schinopsis brasiliensis). Brasília: Embrapa Recursos Genéticos e Biotecnologia, 2001. (Embrapa Recursos Genéticos e Biotecnologia. Circular Técnica, 12).

SILVA, A. Q.et al. Aspectos morfológicos da germinação da baraúna (Schinopsis brasiliensis Engl.) e aroeira (Astronium urudeuva). In: REUNIÃO NORDESTINA DE BOTÂNICA, 1988, João Pessoa. Anais... João Pessoa: Sociedade Botânica do Brasil, 1988. p.6

SOUZA, O.N. de. Chemical constituents of the leaves of Schinopsis brasiliensis Engl. 1990. 207f. Tese (Doctor of Philosophy) - Politechinic of North, London.

TAVARES, M.C.R. Ocorrência de inibidores de germinação em espécies da caatinga. 1982. 66f. Dissertação (Mestrado em Botânica) - Universidade Federal Rural de Pernambuco, Recife. 